\title{
Clave para la identificación de las subfamilias y los géneros de hormigas (Hymenoptera: Formicidae) de Costa Rica
}

\author{
Pablo R. Gutiérrez-Martínez \\ Escuela de Biología, Universidad de Costa Rica, 11501-2060 San José, Costa Rica; pablorgmbiol@hotmail.com
}

Recibido 5-IX-2013 • Corregido 16-XI-2013 Aceptado • 26-I-2014

\begin{abstract}
Identification key for ant subfamilies and genera (Hymenoptera: Formicidae) of Costa Rica. Ants are considered one of the main invertebrate predators and herbivores in Neotropical ecosystems. This versatility is of great economic importance for agriculture, because some ants are considered pests while others play an important role in integrated pest management. Ants can also be indicators of habitat quality, so it is of prime importance to accurately identify them. Currently there are no Spanish keys to the ants of Costa Rica and the use of regional keys may result in misidentifications. To promote a tool for understanding the ant fauna, here I present a list and dichotomous keys for the subfamilies and genera of ants reported from Costa Rica.
\end{abstract}

Keywords: biodiversity, morphology, neotropical.

\section{RESUMEN}

Las hormigas son consideradas uno de los principales depredadores de invertebrados y también prominentes herbívoros en la mayoría de los ecosistemas neotropicales. Esta versatilidad resulta de importancia económica para la agricultura, ya que muchas especies pueden comportarse como plagas en cultivos, pero otras juegan un papel importante en el manejo integrado de plagas. Las hormigas también se consideran indicadoras de la calidad del hábitat, por lo que resulta conveniente una identificación precisa. De momento no existen claves taxonómicas en español para la identificación de las hormigas en Costa Rica. El uso de claves de la región puede resultar en identificaciones erróneas debido, en parte, a cambios recientes en la taxonomía de estos insectos. Con el fin de promover una herramienta para el conocimiento de la fauna de hormigas se presenta una lista y claves dicotómicas para identificar las subfamilias y los géneros de las hormigas de Costa Rica.

Palabras clave: biodiversidad, morfología, neotropical.

Las hormigas integran un componente muy importante en la biodiversidad terrestre, tanto por su diversidad como por su abundancia (Hölldobler \& Wilson, 1990; Folgrarait, 1998). Con más de 12500 especies descritas y muchas otras aun en espera de descripción (Bolton, 2007; Branstetter \& Sáenz, 2012), se estima que el total de la diversidad de las hormigas podría superar las 21000 especies en 574 géneros pero esa cifra podría superar las 25000 especies (Agosti \& Johnson, 2003). Se consideran de los principales depredadores de invertebrados en la mayoría de los ecosistemas terrestres y también prominentes como herbívoros, algunos linajes de hormigas han desarrollado sorprendentes especializaciones como el cultivo de hongos, recolección de semillas, el uso de ligamaza de hemípteros, nidos tejidos, caza cooperativa, parasitismo social y la toma de esclavos, entre otros (Hanson \& Longino, 2006).
Muchas especies de hormigas se consideran de importancia económica, ya que pueden actuar como plagas agrícolas o estar asociadas a otras plagas, además de tener relaciones simbióticas beneficiosas con plantas, otras infringen picaduras dolorosas, además especies introducidas compiten con la fauna local (Della, 2003). Algunas hormigas urbanas pueden causar problemas en los sistemas eléctricos donde nidifican, además pueden ser transmisores de patógenos al contaminar los alimentos humanos, en los hospitales pueden ser vectores de bacterias e incluso de nematodos y protistas (Martínez \& Martínez, 2011). No obstante algunas especies son beneficiosas, ya que constituyen un recurso importante para el control natural de plagas en cultivos (Nicholls, 2008), se han utilizado con éxito en países como Cuba y Brasil (Hanson \& Longino, 2006). Las hormigas conforman uno de los grupos de insectos que puede ser utilizado en 
investigaciones para reflejar cambios en los ecosistemas (Arcila \& Lozano-Zambrano, 2003), con el aumento en la complejidad estructural del ecosistema también aumenta la riqueza y diversidad de especies de hormigas (Estrada \& Fernández, 1999).

A pesar de esos antecedentes aún no existe una clave para la identificación de las hormigas de Costa Rica. No obstante, recursos como los que ofrece la página de internet de John T. Longino (www.evergreen.edu/ants) resultan fundamentales, en la cual aparece un listado de los géneros de hormigas de Costa Rica separados por subfamilias, también listas de especies y claves para algunos géneros, se presentan imágenes e información de las especies. Sin embargo, para identificar mediante claves a subfamilia y a nivel de género Longino refiere a Bolton (1994) y Hölldobler y Wilson (1990).

Debido a la necesidad de una identificación más precisa y con el fin de promover un recurso útil para el estudio de estos insectos en Costa Rica, se presenta una lista y claves dicotómicas, además se considera una herramienta complementaria a los recursos que ofrece la web y otras claves para el Neotrópico.

\section{MATERIALES Y MÉTODOS}

Se hizo revisión bibliográfica de las publicaciones taxonómicas con géneros presentes en Costa Rica. Se elaboró una lista de los géneros de hormigas de Costa Rica con base en www.antweb.org (2013) y www.evergreen.edu/ ants (2013) (Cuadro 1). Se estructuro de tal manera que el orden de los géneros del Cuadro 1 corresponde a cómo van surgiendo en la clave, de igual manera el orden de las figuras.

Las subfamilias de hormigas en la presente clave se caracterizan con base en las claves de Palacio y Fernández (2003), Jaffé (2004), Hanson y Longino (2006) y Olivero, Guerrero y Escárraga (2009). Mientras que los géneros de hormigas se caracterizan con base en las claves de Macklay y Macklay (1989), Palacio y Fernández (2003), Jaffé (2004), Escalante, Ponce y Vásquez (2006), Olivero et al. (2009) y La Polla, Brady y Shattuck (2010).

Además de la revisión literaria, se estudiaron especímenes preservados en la colección de referencia del laboratorio de entomología de la Universidad de Costa Rica, también fotografías de la página de internet de John T. Longino (www.evergreen.edu/ants). La diferenciación entre familias y géneros se hizo mediante una serie de combinaciones de caracteres diagnósticos externos (Figs. 1 y 2). Las ilustraciones se obtuvieron de distintas fuentes mencionadas en las leyendas de las figuras.

\section{RESULTADOS}

Se determinó para Costa Rica 14 subfamilias, con 86 géneros de hormigas en total. Se encontró diferencias en las listas de los géneros de hormigas que viven en Costa Rica, www.antweb.org cuenta con 82 géneros; mientras que en www.evergreen.edu/ants con 85 géneros,

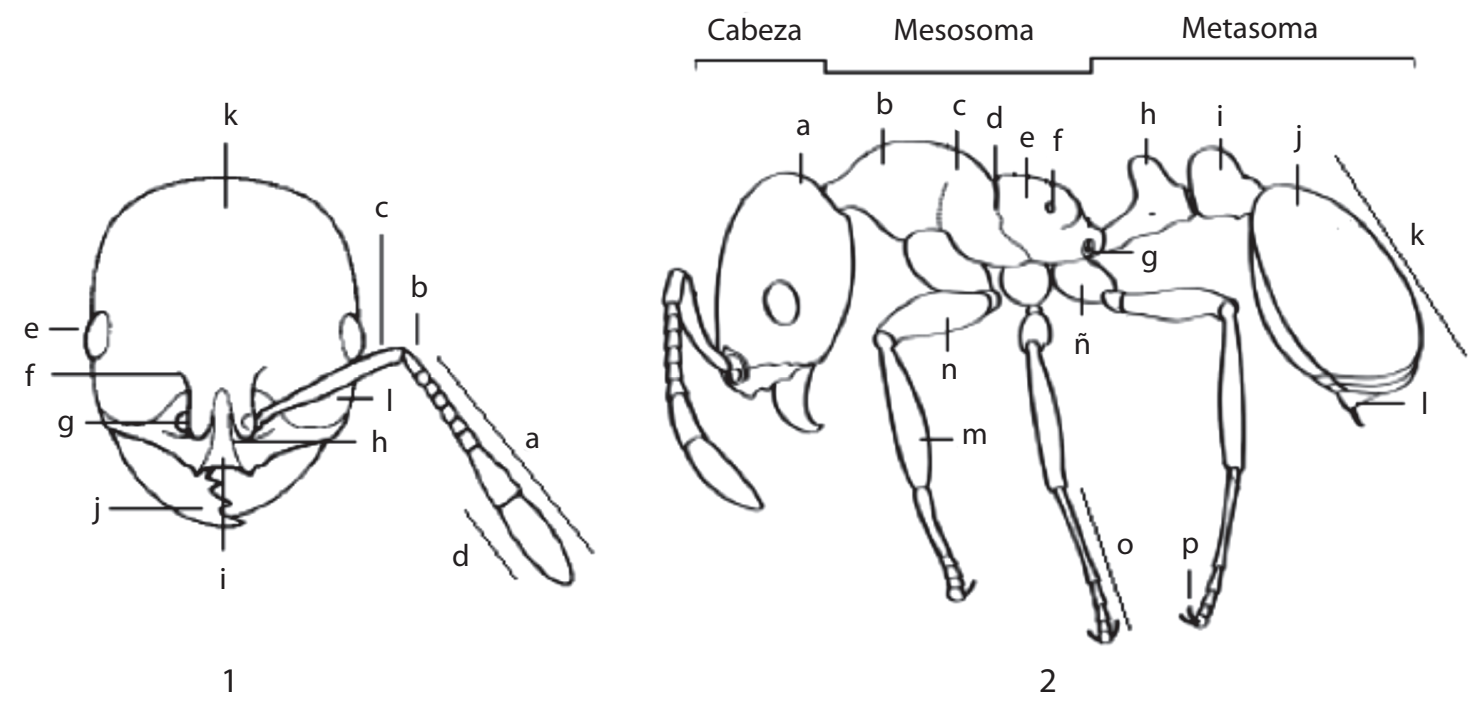

Fig. 1. a: flagelo; b: pedicelo; c: escapo; d: maza; e: ojo; f: carena; g: fosa antenal; h: fosa clípeal; i: clípeo; j: mandíbula; k: vértice; l: gena. Fig. 2. a: occipucio; b: pronoto; c: mesonoto; d: sutura mesometanotal; e: propodeo (I); f: espiráculo; g: glándula metapleural; h: nódulo peciolar (II); i: pospeciolo (III); j: tergo (IV); k: gáster ; I: pigidio; m: tibia; n: fémur; ñ: coxa; o: tarsos; p: garras tarsales. Figura 1 modificada de Palacio y Fernández (2003), figura 2 modificada de Branstetter y Sáenz (2012). 


\section{CUADRO 1}

Lista de subfamilias y géneros de las hormigas de Costa Rica* http://www.evergreen.edu/ants/

\begin{tabular}{|c|c|c|c|}
\hline Subfamilia & Tribu & Género & Figura \\
\hline Agroecomyrmecinae & Agroecomyrmecini & Tatuidris & 3 \\
\hline Paraponerinae & Paraponerini & Paraponera & 4 \\
\hline \multirow[t]{2}{*}{ Amblyoponinae } & Amblyoponinini & Prionopelta & 5 \\
\hline & & Stigmatomma & 6 \\
\hline \multirow[t]{3}{*}{ Proceratiinae } & Probolomyrmecini & Probolomyrmex & 7 \\
\hline & Proceratiini & Discothyrea & 8 \\
\hline & & Proceratium & 9 \\
\hline \multirow[t]{11}{*}{ Ponerinae } & Ponerini & Centromyrmex & 10 \\
\hline & Platythyreini & Platythyrea & 11 \\
\hline & Ponerini & Leptogenys & 12 \\
\hline & & Anochetus & 13 \\
\hline & & Odontomachus & 14 \\
\hline & Traumatomyrmecini & Thaumatomyrmex & 15 \\
\hline & Ponerini & Cryptopone & 16 \\
\hline & & Pachycondyla & 17 \\
\hline & & Belonopelta & 18 \\
\hline & & Simopelta & 19 \\
\hline & & Hypoponera & 20 \\
\hline Leptanilloidinae & Leptanilloidini & Leptanilloides & 21 \\
\hline \multirow[t]{2}{*}{ Cerapachyinae } & Cylindromyrmecini & Cylindromyrmex & 22 \\
\hline & Cerapachyini & Cerapachys & 23 \\
\hline \multirow[t]{4}{*}{ Ecitoninae } & Ecitonini & Eciton & 24 \\
\hline & & Neivamyrmex & 25 \\
\hline & & Nomamyrmex & 26 \\
\hline & & Labidus & 27 \\
\hline Pseudomyrmecinae & Pseudomyrmecini & Pseudomyrmex & 28 \\
\hline \multirow[t]{8}{*}{ Dolichoderinae } & Dolichoderini & Bothriomyrmex & 29 \\
\hline & & Dolichoderus & 30 \\
\hline & & Linepithema & 31 \\
\hline & & Dorymyrmex & 32 \\
\hline & & Azteca & 33 \\
\hline & & Forelius & 34 \\
\hline & & Tapinoma & 35 \\
\hline & & Technomyrmex & 36 \\
\hline \multirow[t]{6}{*}{ Formicinae } & Lasiini & Acropyga & 37 \\
\hline & Plagiolepidini & Myrmelachista & 38 \\
\hline & & Brachymyrmex & 39 \\
\hline & Camponotini & Camponotus & 40 \\
\hline & Plagiolepidini & Nylanderia & 41 \\
\hline & & Paratrechina & 42 \\
\hline \multirow[t]{7}{*}{ Myrmicinae } & Pheidolini & Pheidole & 43 \\
\hline & Stegomyrmecini & Stegomyrmex & 44 \\
\hline & Basicerotini & Basiceros & 45 \\
\hline & & Octostruma & 46 \\
\hline & & Eurhopalothrix & 47 \\
\hline & & Rhopalothrix & 48 \\
\hline & Dacetini & Acanthognathus & 49 \\
\hline
\end{tabular}


CUADRO 1 (Continuación)

Lista de subfamilias y géneros de las hormigas de Costa Rica*

\begin{tabular}{|c|c|c|c|}
\hline Subfamilia & Tribu & Género & Figura \\
\hline & & Pyramica & 50 \\
\hline & & Strumigenys & 51 \\
\hline & Crematogastrini & Crematogaster & 52 \\
\hline & Lenomyrmicini & Lenomyrmex & 53 \\
\hline & Cephalotini & Procryptocerus & 54 \\
\hline & & Cephalotes & 55 \\
\hline & Blepharidattini & Wasmannia & 56 \\
\hline & Attini & Cyphomyrmex & 57 \\
\hline & & Myrmicocrypta & 58 \\
\hline & & Apterostigma & 59 \\
\hline & & Mycocepurus & 60 \\
\hline & & Sericomyrmex & 61 \\
\hline & & Atta & 62 \\
\hline & & Mycetosoritis & 63 \\
\hline & & Trachymyrmex & 64 \\
\hline & & Acromyrmex & 65 \\
\hline & Formicoxenini & Cardiocondyla & 66 \\
\hline & Stenammini & Lachnomyrmex & 67 \\
\hline & Myrmicini & Hylomyrma & 68 \\
\hline & Tetramoriini & Tetramorium & 69 \\
\hline & Stenammini & Rogeria & 70 \\
\hline & Adelomyrmecinini & Adelomyrmex & 71 \\
\hline & Formicoxenini & Nesomyrmex & 72 \\
\hline & & Temnothorax & 73 \\
\hline & Myrmecinini & Xenomyrmex & 74 \\
\hline & Solenopsidini & Monomorium & 75 \\
\hline & & Megalomyrmex & 76 \\
\hline & Pheidolini & Aphaenogaster & 77 \\
\hline & Stenammini & Stenamma & 78 \\
\hline & Solenopsidini & Carebara & 79 \\
\hline & & Carebarella & 80 \\
\hline & & Solenopsis & 81 \\
\hline & & Tranopelta & 82 \\
\hline & Stenammini & Bariamyrma & \\
\hline \multirow[t]{3}{*}{ Ectatomminae } & Typhlomyrmecini & Typhlomyrmex & 83 \\
\hline & Ectatommini & Ectatomma & 84 \\
\hline & & Gnamptogenys & 85 \\
\hline \multirow[t]{2}{*}{ Heteroponerinae } & Heteroponerini & Acanthoponera & 86 \\
\hline & & Heteroponera & 87 \\
\hline
\end{tabular}

*con base en las listas presentes en www.antweb.org y www.evergreen.edu/ants/. Filogenia según la clasificación planteada por Bolton (2003), Fernández y Sendoya (2004), Brady, Schultz, Fisher y Ward (2006), Ward (2010), La Polla et al. (2010), Yoshimura \& Fisher (2012). 
esta última probando ser una de las principales herramientas para la identificación de las hormigas de Costa Rica. La presente clave incluye 85 géneros, no incluye el género Bariamyrma, este género se incluye en la lista del Cuadro 1.

\section{Clave para las subfamilias de hormigas de Costa Rica}

1. Pigidio grande y aplanado con hilera de dientes gruesos y erguidos a cada lado. Cerapachyinae (Fig. 22 y Fig. 23)

Pigidio sin dientes gruesos, a veces con setas cortas y rígidas. 2

2. Con peciolo y pospeciolo, salvo Cheliomyrmex en Ecitoninae que no tiene pospeciolo (género no reportado para Costa Rica). 3

Sin pospeciolo. 7

3. Ojos ausentes o representados por un único omatidio; inserciones antenales no ocultas del todo por lóbulos frontales. 4

Ojos con muchos omatidios e inserciones antenales usualmente ocultas del todo por los lóbulos frontales. 5

4. Sutura promesonotal presente y sobresaliente en vista dorsal; gáster relativamente alargado, tergo II apenas más corto que tergo I. Leptanilloidinae (Fig. 21)

Sutura promesonotal de vestigial a ausente; gáster más grueso, tergo menos de la mitad que tergo I. Ecitoninae (Fig. 24 a Fig. 27)

5. Margen posterior del clípeo no se extiende más allá del margen anterior de las fosas antenales; tres ocelos presentes; ojos grandes; esbeltas; sutura presente entre el pronoto y mesonoto. Pseudomyrmecinae (Fig. 28)

Margen posterior del clípeo se extiende más allá del margen anterior de las fosas antenales, separándolas; ocelos casi siempre ausentes; forma del cuerpo variable; pronoto fusionado a mesonoto. 6

6. Fosetas antenales cerca de la mitad del frente de la cabeza; mandíbulas usualmente se cruzan, aunque sean sus ápices, al estar cerradas; tibia posterior rara vez con espolón pectinado. Myrmicinae (Fig. 43 a Fig. 82)

Fosetas antenales muy separadas y más cerca de los lados de la cabeza que de la mitad; mandíbulas se oponen, no se cruzan al estar cerradas; tibia media y posterior con espolón pectinado. Agroecomyrmecinae (Fig. 3)

7. Aguijón presente; gáster relativamente alargado y cilíndrico. 8

Aguijón ausente; gáster frecuentemente corto y subesférico. 13

8. Peciolo no muy separado del gáster y sin superficie posterior. Amblyoponinae (Fig. 5 y Fig. 6)

Peciolo bien separado del gáster y con superficie posterior. 9

9. Inserciones antenales horizontales, expuestas y ubicadas en margen anterior de cabeza; sutura promesonotal fusionada o ausente. Proceratiinae (Fig. 7 a Fig. 9)

Inserciones antenales por lo menos parcialmente tapadas por lóbulos frontales y ubicadas detrás del margen anterior de la cabeza; sutura promesonotal presente. 10

10. Margen lateral de hipopigio con una hilera de espinas verticales; escrobas antenales se extienden hacia arriba del ojo y luego doblan hacia abajo detrás del ojo. Paraponerinae (Fig. 4)

Margen lateral de hipopigio sin espinas; escrobas ausentes o no como lo anterior. 11

11. Fosas antenales fusionadas con los lobulos frontales, los últimos convergentes en la parte posterior. Ponerinae (Fig. 10 a Fig. 20)

Fosas antenales no fusionadas con lobulos frontales, los últimos no convergentes en la parte posterior. 12

12. Cabeza con carena longitudinal en la parte media que se extiende desde el margen clípeal hasta el margen posterior de la cabeza Heteroponerinae (Fig. 86 y Fig. 87)

Cabeza sin carena longitudinal en la parte media. Ectatomminae (Fig. 83 a Fig. 85)

13. Tergo del quinto segmento del gáster (último segmento abdominal) grande y visible; propodeo casi siempre redondeado o ligeramente angulado visto de perfil; ápice del gáster con la abertura cloacal semicircular a circular, frecuentemente bordeada por setas. Formicinae (Fig. 37 a Fig. 42)

Tergo del quinto segmento del gáster pequeño y usualmente no visible; propodeo algunas veces notablemente angulado con protuberancias, laminas o espinas conspicuas particularmente en especies de más de cinco milímetros, ápice del gáster con la abertura cloacal en forma de ranura transversal y sin una franja circular de setas. Dolichoderinae (Fig. 29 a Fig. 36) 

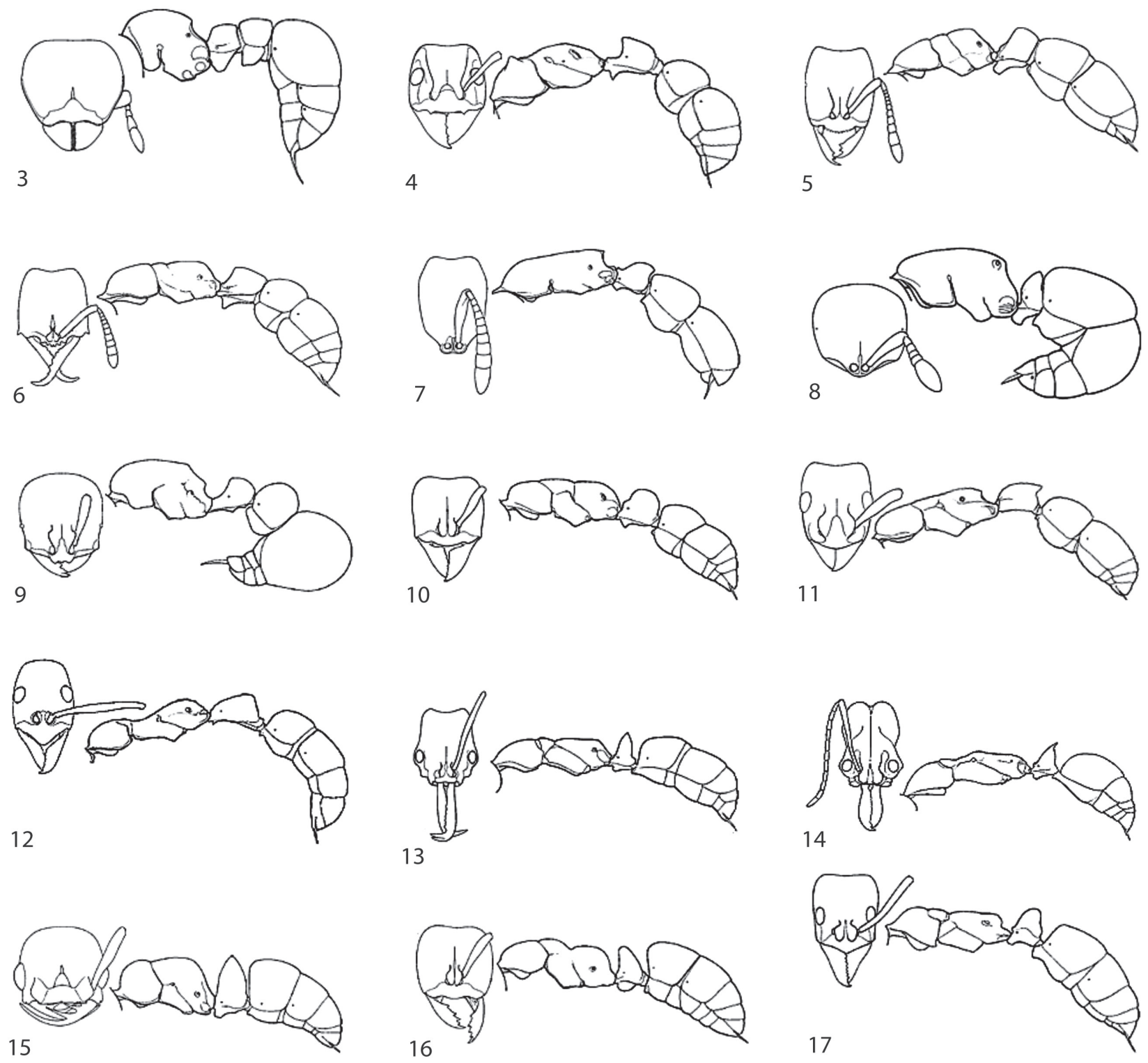

Fig. 3. Tatuidris. Fig. 4. Paraponera. Fig. 5. Prionopelta. Fig. 6. Stigmatomma. Fig. 7. Probolomyrmex. Fig. 8. Discothyrea. Fig. 9. Proceratium. Fig. 10. Centromyrmex. Fig. 11. Platythyrea. Fig. 12. Leptogenys. Fig. 13. Anochetus. Fig. 14. Odontomachus. Fig. 15. Thaumatomyrmex. Fig. 16. Cryptopone. Fig. 17. Pachycondyla. Figura 3 modificada de Fernández (2003a). Figuras 4, 5, 6,7, 8, 9, 10, $11,12,13,14,15,16$ y 17 modificadas de Lattke (2003). 


\section{Clave para los géneros de hormigas de Costa Rica}

\section{Amblyoponinae, Agroecomyrmecinae, Paraponerinae, Proceratiinae, Ponerinae}

1. Mandíbulas triangulares con dientes pequeños, cuando están cerradas, sus bordes masticadores están en contacto sobre toda su superficie, jamás se cruzan; cabeza con pelos largos; espolón de la tibias media y posterior pectinada; antena con siete segmentos (Agroecomyrmecinae). Tatuidris (Fig. 3)

Sin esta combinación de caracteres. 2

2. Hormigas grandes, con un surco fuertemente marcado que recorre desde las inserciones antenales hasta por encima y detrás de los ojos; pigidio bordeado lateralmente por una serie de dentículos (Paraponerinae). Paraponera (Fig. 4)

Tamaño variable, sin surco fuerte que llega detrás de los ojos; pigidio sin una hilera lateral de dentículos, a lo sumo dos o tres dientes masivos apicales. 3

3. Sin constricción en la unión entre el peciolo y el primer segmento del gáster; borde anterior del clípeo con una serie de dientecitos. (Amblyoponinae). 4

Constricción entre el peciolo y pospeciolo usualmente fuerte; borde anterior del clípeo sin hilera de dientecitos, a lo sumo tres o cuatro. 5

4. Mandíbulas cortas y estrechas, con tres dientes y adyacentes al clípeo cuando están cerradas. Prionopelta (Fig. 5)

Mandíbulas largas y usualmente lineales con más de tres dientes y separadas del clípeo cuando están cerradas. Stigmatomma (Fig. 6)

5. Inserciones antenales totalmente expuestas, sin estar cubiertas por los lóbulos antenales (Proceratiinae). 6

Inserciones antenales cubiertas, por lo menos en parte, por expansiones laterales de las carenas frontales (Ponerinae). 8

6. Ápice del gáster fuertemente doblado anteroventralmente. 7

Ápice del gáster no fuertemente doblado anteroventralmente. Probolomyrmex (Fig. 7)

7. Antena termina en una maza prominente. Discothyrea (Fig. 8)

Antena sin maza apical. Proceratium (Fig. 9)

8. En vista lateral la articulación entre el peciolo y pospeciolo está situado hacia el borde ventral del perfil anterior del peciolo, el perfil anterior del pospeciolo superior a la inserción, es mucho más largo que el perfil inferior a esta. 10

En vista lateral la articulación entre el peciolo y pospeciolo está situado en la mitad del perfil anterior del peciolo, la longitud del perfil superior a la inserción no es mucho más larga que la parte ventral de la inserción. 9

9. Superficie exterior de la mesotibia sin setas espiniformes; integumento liso y brillante; sin ojos. Centromyrmex (Fig. 10)

Superficie exterior de la mesotibia con setas espiniformes; integumento diferente, nunca totalmente liso y brillante; ojos presentes pero a veces atrofiados. Platythyrea (Fig. 11)

10. Garras tarsales pectinadas. Leptogenys (Fig. 12)

Garras tarsales simples o dentadas, nunca pectinadas. 11

11. Mandíbulas rectas, articuladas en el medio del margen anterior de la cabeza, paralelas una a la otra cuando cerradas. 12

Mandíbulas articuladas lateralmente del margen anterior de la cabeza, no rectas ni paralelas cuando cerradas. 13

12. Carena formando una curva amplia no interrumpida a través del margen posterior de la cabeza; líneas apofisiales cefálicas ausentes; nudo del peciolo varía desde escamiforme hasta bidentado pero no cónico o puntiagudo. Anochetus (Fig. 13)

Carena convergiendo en forma de $\mathrm{V}$ en medio margen posterior cefálico; líneas apofisiales cefálicas presentes y bien definidas; nudo del peciolo con ápice dorsal generalmente cónico o puntiagudo. Odontomachus (Fig. 14)

13. Mandíbulas delgadas con tres o cuatro dientes espiniformes. Thaumatomyrmex (Fig. 15)

Mandíbulas variables pero nunca con dientes espiniformes. 14

14. Tibias medias y posteriores con dos espolones apicales. 15

Tibias medias y posteriores con un solo espolón apical. 16

15. Superficie exterior de la mesotibia con setas espiniformes; mandíbulas con una pequeña fosa laterobasal. Cryptopone (Fig. 16)

Superficie exterior de la mesotibia rara vez con setas espiniformes; mandíbulas carecen de una fosa laterobasal. Pachycondyla (Fig. 17) 

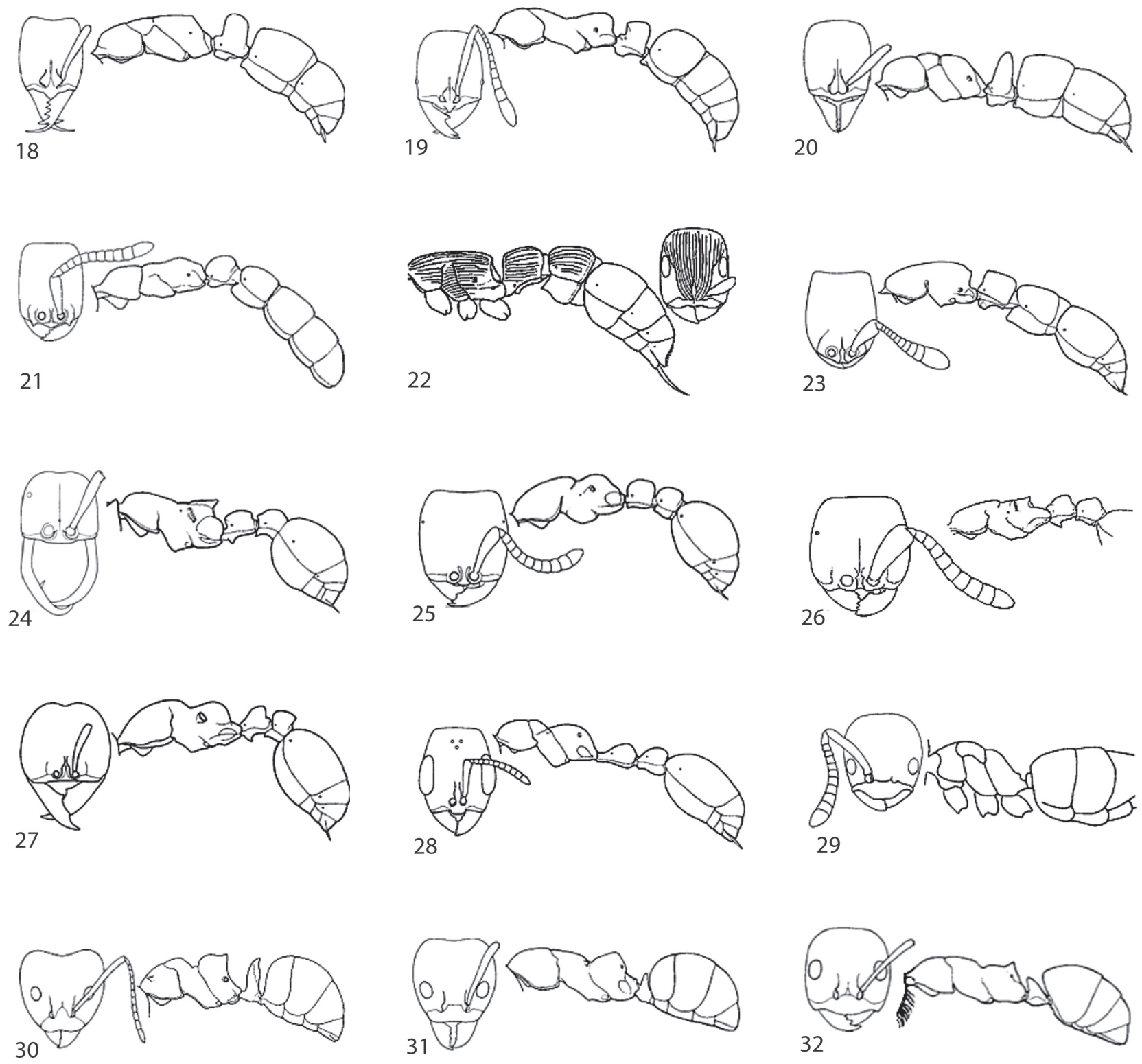

Fig. 18. Belonopelta. Fig. 19. Simopelta. Fig. 20. Hypoponera. Fig. 21. Leptanilloides. Fig. 22. Cylindromyrmex. Fig. 23. Cerapachys. Fig. 24. Eciton. Fig. 25. Neivamyrmex. Fig. 26. Nomamyrmex. Fig. 27. Labidus. Fig. 28. Pseudomyrmex. Fig. 29. Bothriomyrmex. Fig. 30. Dolichoderus. Fig. 31. Linepithema. Fig. 32. Dorymyrmex. Figuras 18, 19 y 20 modificadas de Lattke (2003), 21 de modificada de Brandão (2003), 22 y 23 modificadas de Mackay (2003), 24, 25, 26 y 27 modificadas de Palacio (2003), 28 modificada de Ward (2003), 29, 30, 31 y 32 modificadas de Cuezzo (2003). 
16. Mandíbulas con cinco dientes, rara vez seis dientes, el último notablemente largo y acicular. Belonopelta (Fig. 18)

Mandíbula con un número diferente de dientes, o si igual a cinco entonces el diente apical no es acicular. 17

17. Mandíbulas con tres a cinco dientes grandes, los dos últimos separados a una notable distancia de los basales; lóbulo medio clipeal ampliamente triangular y proyectado sobre el resto del clípeo. Simopelta (Fig. 19)

Mandíbulas de configuración diferente, los dientes apicales contiguos a los basales; lóbulo medio del clípeo nunca de forma triangular y no proyectado hacia adelante. Hypoponera (Fig. 20)

\section{Cerapachyinae y Leptanilloidinae}

1. Pigidio con una hilera de pequeñas espinas o dientecitos en cada lado (Cerapachyinae). 2

Pigidio sin hilera de espinas o dientecitos (Leptanilloidinae). Leptanilloides (Fig. 21)

2. Cuerpo con estrías, sin pilosidad; cabeza con surcos antenales presentes, sin carena curvada. Cylindromyrmex (Fig. 22)

Cuerpo sin estrías, con pilosidad variable; cabeza sin surcos antenales presentes, con carena curvada. Cerapachys (Fig. 23)

\section{Ecitoninae}

1. El segundo artejo del funículo de la antena por lo menos dos veces más largo que el primero; las mandíbulas de los soldados son grandes y en forma de ganzúas, encorvadas hacia dentro. Eciton (Fig. 24)

El segundo artejo del funículo de la antena es más corto que dos veces la longitud del primero; en los soldados sus mandíbulas no son tan largas. 2

2. Uñas tarsales sin dientecillos; longitud de las obreras mayores generalmente de menos de ocho milímetros. Neivamyrmex (Fig. 25)

Uñas tarsales con dientecillos en la parte interior; longitud de las obreras mayores generalmente de más de ocho milímetros. 3

3. Escapo muy grueso, su anchura es de más de $1 / 3$ de su longitud total. Nomamyrmex (Fig. 26)
Escapo y funículo corto y delgado, su anchura apical es de menos de $1 / 3$ de su longitud total. Labidus (Fig. 27)

\section{Pseudomyrmecinae}

1. Antenas con doce segmentos; cuerpo alargado; ojos grandes; ocelos presentes. Pseudomyrmex (Fig. 28)

\section{Dolichoderinae}

1. Diámetro del ojo menor que el máximo diámetro del escapo y ubicados muy adelante; margen frontal del clípeo presenta entre dos y doce setas que son de la misma longitud que las mandíbulas cerradas; espiráculo propodeal a menudo redondeado. Bothriomyrmex (Fig. 29)

Sin esta combinación de caracteres. 2

2. Cutícula aparentemente gruesa, dura o esculturada; pronoto redondeado o con espinas o con ángulos anterolaterales. Dolichoderus (Fig. 30)

Cutícula aparentemente delgada, flexible y sin enculturación notable; pronoto siempre redondeado. 3

3. Palpos maxilares de tres segmentos; cabeza de forma semi-rectangular; margen anterior del clípeo con una concavidad amplia aunque poco profunda. Linepithema (Fig. 31)

Palpos maxilares de seis segmentos; tamaño y forma cefálica variable,margen anterior del clípeo sin una concavidad. 4

4. Propodeo con un tubérculo agudo o proceso conoidal sobre el dorso; tercer segmento del palpo maxilar más largo que segmentos cuatro, cinco y seis juntos; psamoforo presente con distinto grado de desarrollo. Dorymyrmex (Fig. 32)

Propodeo convexo, sin protuberancias notables; tercer segmento del palpo maxilar de una longitud comparable a los demás. 5

5. Pronoto y mesonoto en perfil notablemente curvado, no forma una línea recta; nódulo peciolar con protuberancia más larga que ancha en vista lateral; algunas polimórficas y a veces con ocelos. Azteca (Fig. 33)

Pronoto y mesonoto forman una línea recta o curva muy suave vistos de perfil; nódulo más alto que largo; obreras monomórficas, nunca con ocelos. 6

6. Peciolo atrofiado, casi ausente, oculto por el gáster en vista lateral. 7 

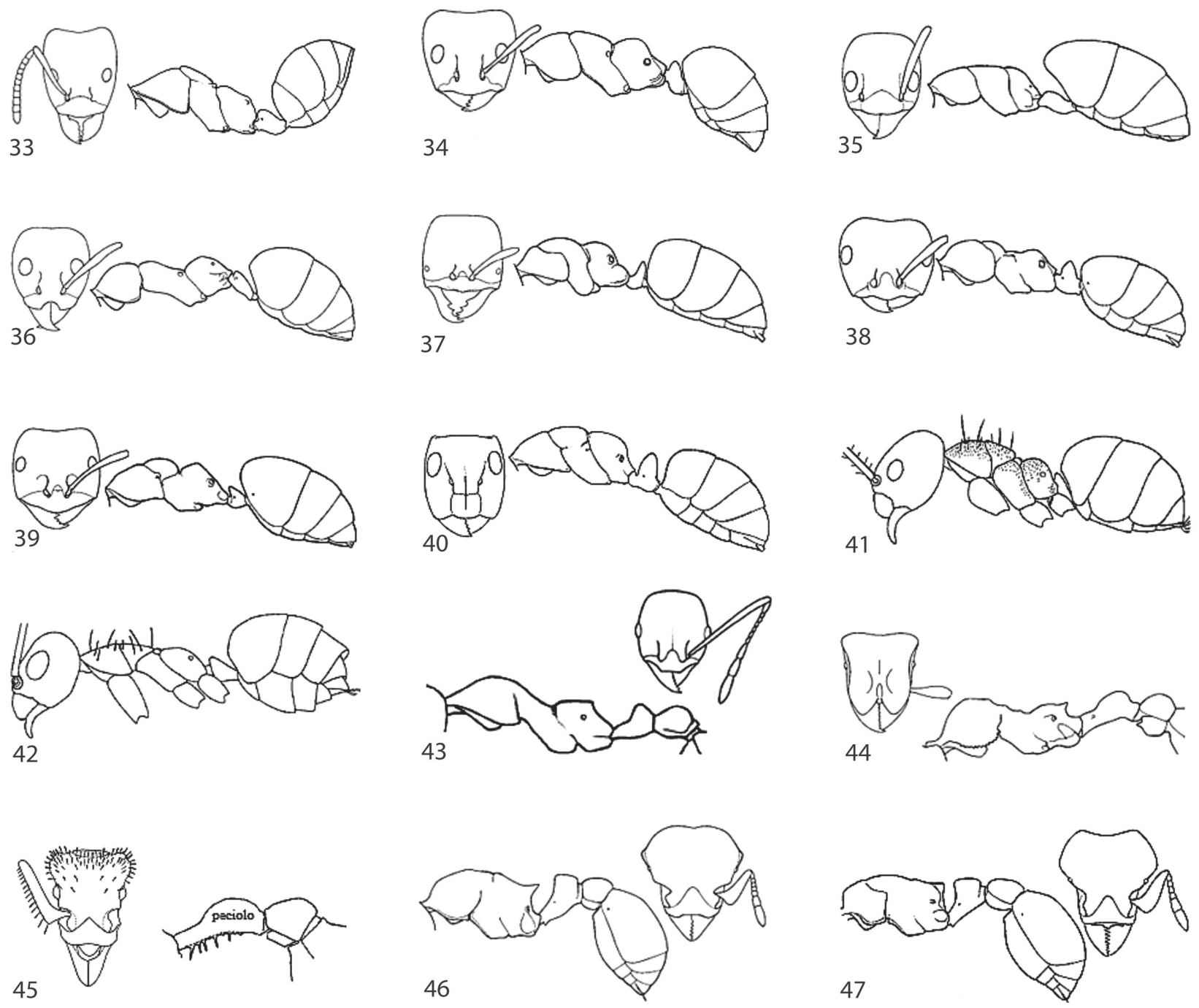

Fig. 33. Azteca. Fig. 34. Forelius. Fig. 35. Tapinoma. Fig. 36. Technomyrmex. Fig. 37. Acropyga. Fig. 38. Myrmelachista. Fig. 39. Brachymyrmex. Fig. 40. Camponotus. Fig. 41. Nylanderia. Fig. 42. Paratrechina. Fig. 43. Pheidole. Fig. 44. Stegomyrmex. Fig. 45. Basiceros. Fig. 46. Octostruma. Fig. 47. Eurhopalothrix. Figuras 33, 34, 35 y 36 modificadas de Cuezzo (2003). Figuras 37, 38, 39, 40, 43, 44, 46 y 47 modificadas de Fernández (2003b). Figuras 41 y 42 modificadas de Trager (1984). Figura 45 modificada de Brown \& Kempf (1960). 
Peciolo fácilmente visible de manera lateral, no está oculto por el gáster. Forelius (Fig. 34)

7. En vista dorsal el gáster presenta cuatro segmentos ya que la quinta esta doblada y el ano no parece estar en el ápice. Tapinoma (Fig. 35)

En vista dorsal, el gáster presenta cinco segmentos y el ano es evidentemente apical. Technomyrmex (Fig. 36)

\section{Formicinae}

1. Antenas con un máximo de once segmentos. 2 Antena con doce segmentos. 4

2. Mandíbulas esbeltas, casi erectas y con el borde masticador muy oblicuo y tridentado; ojos atrofiados y anterolaterales; antena con nueve o menos segmentos. Acropyga (Fig. 37)

Mandíbulas robustas y el borde masticador con cuatro o más dietes; ojos más grandes; antena con nueve o diez segmentos. 3

3. Antenas apicalmente forman una maza de dos o tres segmentos; el nódulo peciolar es erecto y está expuesto. Myrmelachista (Fig. 38)

Antenas sin maza apical; nódulo peciolar inclinado hacia adelante y escondido debajo del gáster. Brachymyrmex (Fig. 39)

4. Inserciones antenales bastante separadas del margen posterior del clípeo; perfil del mesosoma generalmente casi erecto o gradualmente convexo, rara vez discontinuo; orificio de la glándula metapleural ausente. Camponotus (Fig. 40)

Inserciones antenales situadas cerca o en contacto con el margen posterior del clípeo; perfil del mesosoma claramente discontinuo; orificio de la glándula metapleural presente. 5

5. Mandíbulas típicamente con seis a siete dientes, rara vez con cinco dientes, si con cinco dientes; mesotórax con constricción inmediatamente posterior del pronoto; con setas erectas en la cabeza, escapo y el dorso del mesosoma. Nylanderia (Fig. 41)

Mandíbulas siempre con cinco dientes; mesotórax no constreñido inmediatamente posterior del pronoto; con setas erectas abundantes pero no presentes en los escapos. Paratrechina (Fig. 42)

\section{Myrmicinae}

1. Constricción entre el mesonoto y propodeo bien marcada; peciolo con péndulo largo; maza antenal de tres segmentos; obreras dimórficas y polimórficas. Pheidole (Fig. 43)

Sin esta combinación de caracteres. 2

2. Cabeza más o menos cordiforme (forma de corazón), estrecha anteriormente, si es alargada el peciolo y pospeciolo con protuberancias fungiformes (forma de hongo); ángulos occipitales de la cabeza carecen de espinas; surcos antenales generalmente presentes. 3

Cabeza diferente, pero si es cordiforme entonces los ángulos occipitales de la cabeza son espinosos o tuberculados, o los pelos son esbeltos y las mandíbulas normalmente anchas con un borde apical denticulado; peciolo sin protuberancias fungiformes; surcos antenales generalmente ausentes. 10

3. Carenas frontales forman un escudo con dos surcos sobre el clípeo; mandíbulas falcadas (forma de hoz). Stegomyrmex (Fig. 44)

Carenas frontales no forman escudo con dos surcos sobre el clípeo; mandíbulas no falcadas. 4

4. Surco antenal profundo; protuberancias parecidas a hongos sobre el peciolo ausentes; ojos situados en o más allá de la media distancia cefálica y por encima del surco antenal. 5

Surco antenal ausente, o si tiene uno, usualmente es corto; protuberancias fungiformes presentes; ojos situados debajo de la media distancia cefálica y debajo del escapo. 8

5. Antenas de doce segmentos. Basiceros (Fig. 45)

Antena de siete a ocho segmentos. 6

6. Antena de ocho segmentos. Octostruma (Fig. 46) Antena de siete segmentos. 7

7. Mandíbulas triangulares, borde masticador seriamente denticulado y amplio contacto entre las dos mandíbulas. Eurhopalothrix (Fig. 47)

Mandíbulas lineales, cruzándose solamente hacia los ápices, con un diente apical largo y conspicuo. Rhopalothrix (Fig. 48)

8. Antenas de once segmentos; mandíbulas casi tan largas como la cabeza, con una espina basal prominente. Acanthognathus (Fig. 49) 

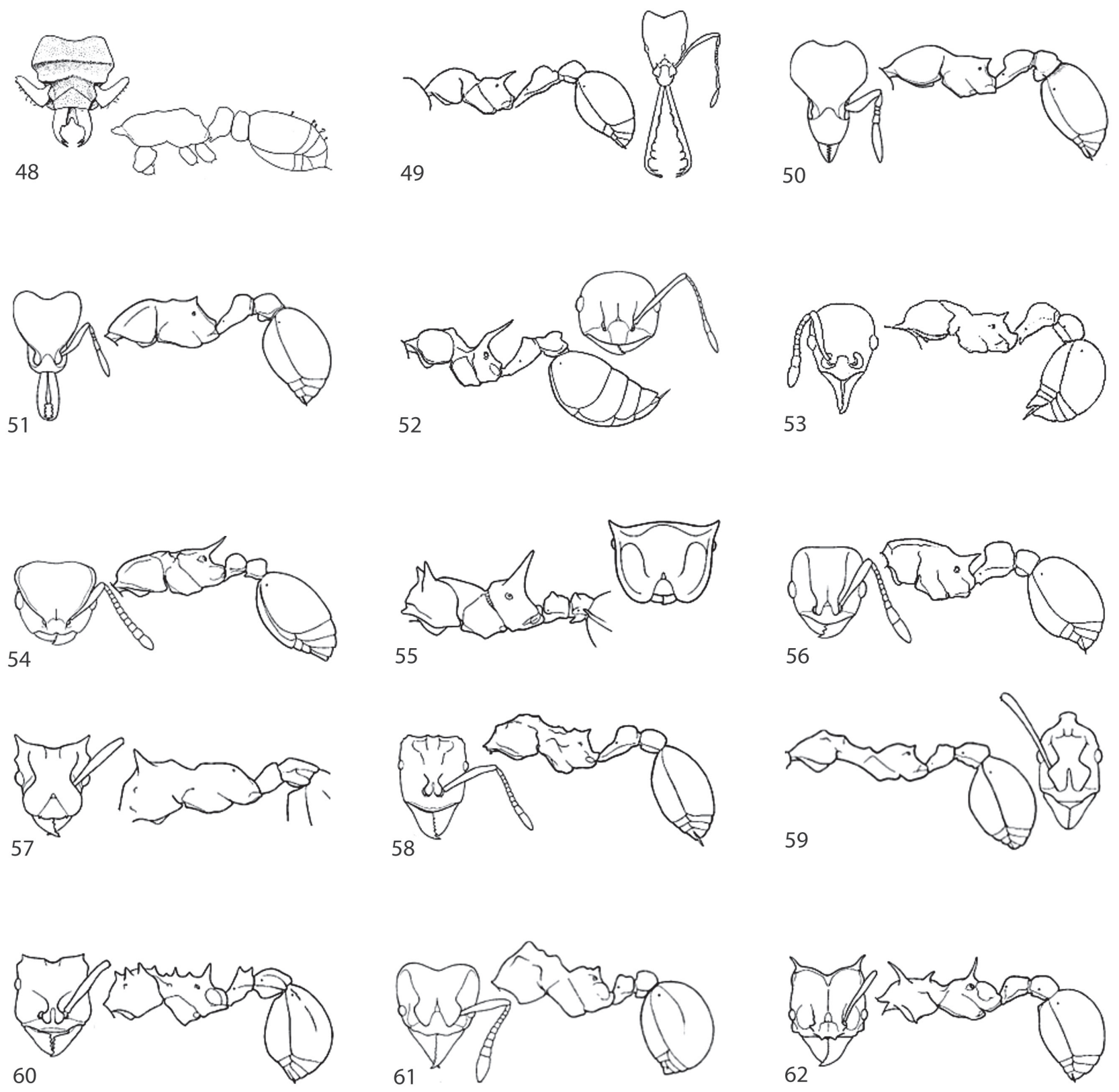

Fig. 48. Rhopalothrix. Fig. 49. Acanthognathus. Fig. 50. Pyramica. Fig. 51. Strumigenys. Fig. 52. Crematogaster. Fig. 53. Lenomyrmex. Fig. 54. Procryptocerus. Fig. 55. Cephalotes. Fig. 56. Wasmannia. Fig. 57. Cyphomyrmex. Fig. 58. Myrmicocrypta. Fig. 59. Apterostigma. Fig. 60. Mycocepurus. Fig. 61. Sericomyrmex. Fig. 62. Atta. Figura 48 modificada de Weber (1934). Figuras 49, 50, 51, 52,53, 54 55, $56,57,58,59,60,61$ y 62 modificadas de Fernández (2003b). 
Antenas de seis o menos segmentos, mandíbulas distintas a lo anterior. 9

9. Mandíbulas semitriangulares, seriamente denticuladas; labro con lóbulos muy largos; cavidad bucal corta y ancha. Pyramica (Fig. 50)

Mandíbulas lineales o semilineales con dos o más dientes apicales largos; labro con lóbulos poco desarrollados; cavidad bucal alargada. Strumigenys (Fig. 51)

10. Pospecíolo articulado antero dorsalmente al primer segmento del gáster; gáster en vista dorsal cordiforme y con el ápice agudo. Crematogaster (Fig. 52)

Pospecíolo articulado al ápice anterior del primer segmento del gáster; gáster dorsalmente es ovaloide. 11

11. Mandíbulas alargadas y con margen masticatorio opuesto, jamás cruzándose, incluso en el ápice. Lenomyrmex (Fig. 53)

Mandíbulas de forma variable, margen masticador cerrado se cruza, aunque sea el ápice. 12

12. Mandíbulas planas y con dientes de igual tamaño; cabeza y tórax usualmente con espinas, dientes o bordes angulosos. 13

Sin esta combinación de caracteres. 14

13. Carenas frontales poco expandidas; genas visibles en vista frontal; el escapo se extiende más allá del margen posterior del ojo. Procryptocerus (Fig. 54)

Carenas frontales expandidas y cubren las genas; el escapo no se extiende más allá del margen posterior del ojo; cabeza apenas tan larga como ancha. Cephalotes (Fig. 55)

14. Alveolos antenales parciales o totalmente cubiertos por los lóbulos frontales; mandíbulas sin diente en el margen basal y con más de tres dientes en el margen masticador; antenas de once segmentos. 15

Sin esta combinación de caracteres. 24

15. Aguijón bien desarrollado y usualmente visible; hormigas pequeñas, menos de dos milímetros; mandíbulas con menos de 6 dientes. Wasmannia (Fig. 56)

Aguijón con poco desarrollo y usualmente no visibles; hormigas de tamaño variable; mandíbulas con numero de dientes variable. 16

16. Cutícula dorsal del gáster liso o con fosetas muy finas, pelos finos presentes. 17

Cutícula dorsal del gáster con tubérculos o pelos gruesos. 22
17. Pelos dorsales del cuerpo, escamosos o aplicados (pegados al cuerpo). 18

Pelos dorsales del cuerpo simples o ausentes. 19

18. Lóbulos de las carenas frontales muy expandidos, usualmente exceden en anchura a la distancia entre los ojo; mandíbulas con cinco a siete dientes cada una. Cyphomyrmex (Fig. 57)

Lóbulos de las carenas frontales con poca expansión, nunca tan anchos como la mitad de la distancia interocular; mandíbulas con siete o más dientes; dorso cefálico y mesosomal con pelos escamiformes sobre tubérculos. Myrmicocrypta (Fig. 58)

19. Dorso mesosomal sin espinas ni tubérculos; occipucio liso y redondeado; pilosidad larga y flexible; lóbulos frontales juntos. Apterostigma (Fig. 59)

Sin esta combinación de caracteres. 20

20. Espinas pronotales forman un circulo o corona. Mycocepurus (Fig. 60)

Espinas pronotales dispuestas de otra manera. 21

21. Occipucio y mesosoma sin espinas, a lo sumo con tubérculos pequeños sobre el pronoto, pilosidad flexible y densa cubre la mayor parte del cuerpo; monomórficas; cabeza cordiforme. Sericomyrmex (Fig. 61)

Espinas occipitales presentes, no así en obreras menores; mesosoma con tres pares de espinas y poca pilosidad; altamente polimórficas. Atta (Fig. 62)

22. Surcos antenales llegan al occipucio; pronoto con prominentes tubérculos dorsales; pilosidad larga y flexible. Mycetosoritis (Fig. 63)

Surcos antenales más breves; tubérculos o espinas sobre la superficie dorsal del cuerpo. 23

23. Distancia entre el ojo y la mandíbula usualmente mucho mayor que el diámetro del ojo; espinas occipitales generalmente ausentes o muy débiles. Trachymyrmex (Fig. 64)

Distancia entre el ojo y la mandíbula igual o inferior al diámetro del ojo; espinas o tubérculos occipitales prominentes; mesosoma con cuatro pares de espinas. Acromyrmex (Fig. 65)

24. Cabeza y mesosoma sin pelos dorsales y con fosetas muy finas; perfil lateral del mesosoma aplanado; sutura promesonotal débil o ausente y sutura metanotal presente; con masa antenal de tres segmentos; propodeo con espinas, cuando carece de espinas no tienen masa antenal de tres segmentos. Cardiocondyla (Fig. 66)

Cabeza y mesosoma por lo menos con algunos pelos erectos o semierectos; sutura mesosomales variables 

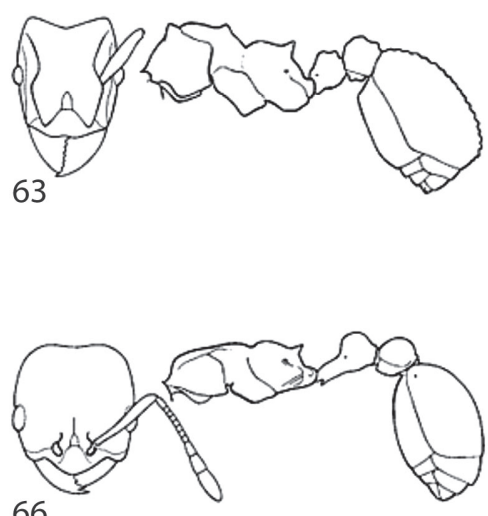

66
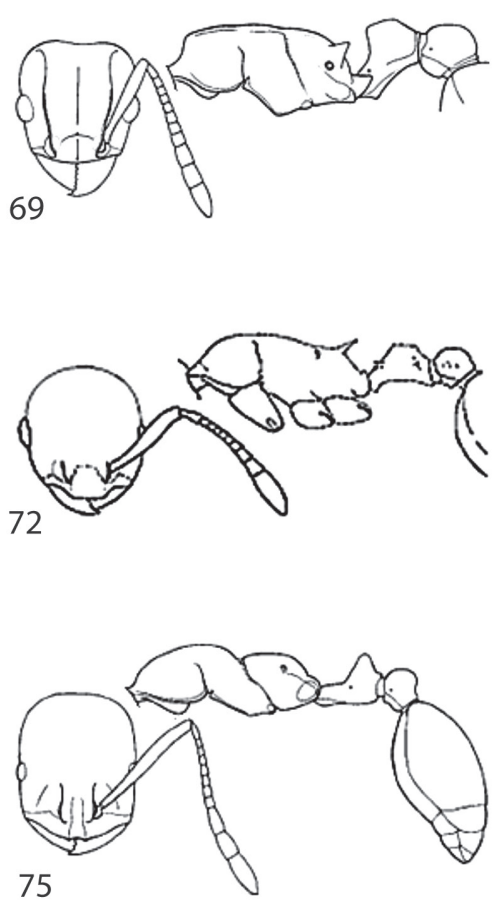
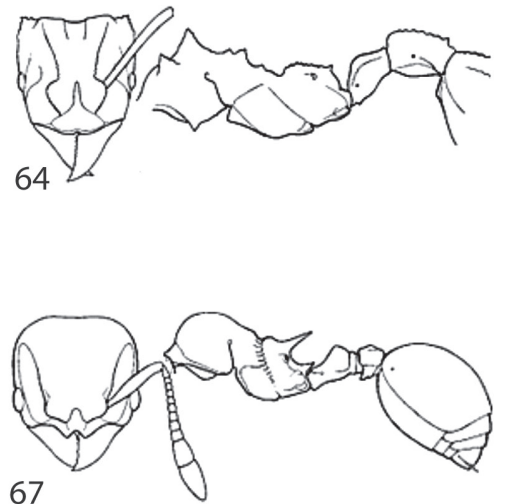

67
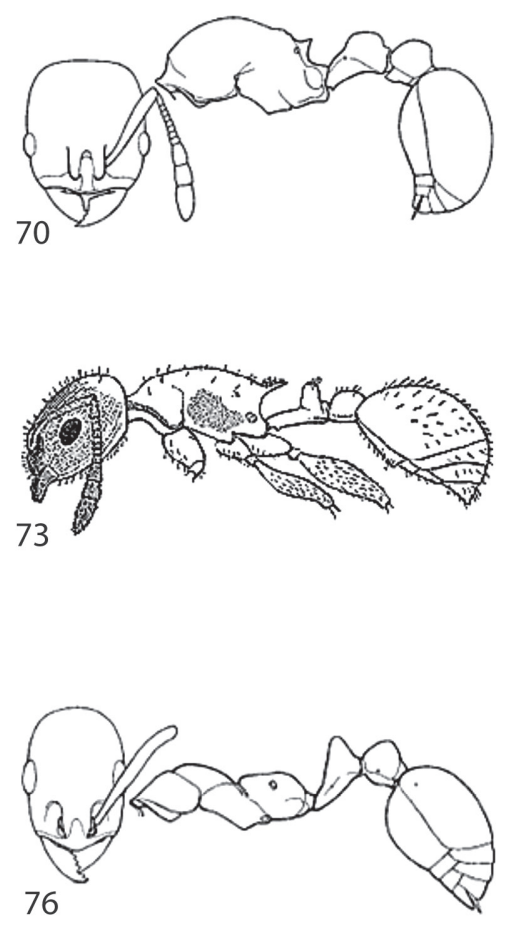
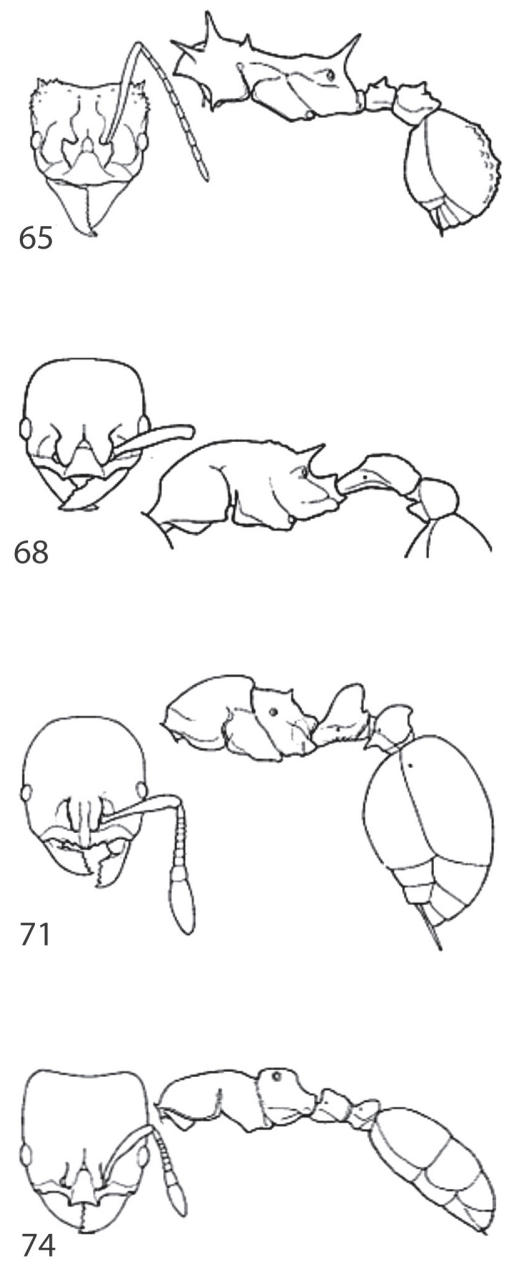

74

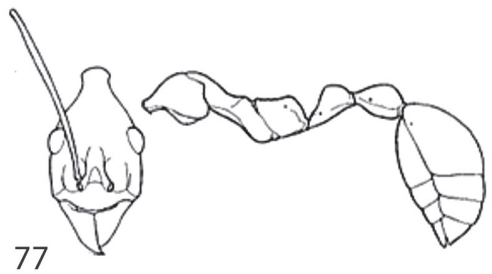

Fig. 63. Mycetosoritis. Fig. 64. Trachymyrmex. Fig. 65. Acromyrmex. Fig. 66. Cardiocondyla. Fig. 67. Lachnomyrmex. Fig. 68. Hylomyrma. Fig. 69. Tetramorium. Fig. 70. Rogeria. Fig. 71. Adelomyrmex. Fig. 72. Nesomyrmex. Fig. 73. Temnothorax. Fig. 74. Xenomyrmex. Fig. 75. Monomorium. Fig. 76. Megalomyrmex. Fig. 77. Aphaenogaster. Figura 72 modificada de Hölldobler \& Wilson (1990), 73 de Smith (1939). Figuras 63, 64, 65, 66, 67, 68, 69,70, 71, 74, 75, 76 y 77 de Fernández (2003b). 
y su perfil usualmente no es aplanado, comúnmente son lisas y brillantes o muy arrugadas sobre el dorso cefálico. 25

25. Surco antenal profundo y bordeado por una carena que se extiende delante del ojo hasta el final del surco, superficie de los surcos antenales lisos y brillantes, contrastando con la superficie cefálica densamente esculturada; antena de doce segmentos, con mazo de dos segmentos; propodeo con dos espinas. Lachnomyrmex (Fig. 67)

Surco antenal usualmente ausente, pero si existe entonces su borde posterior no es bordeado por una carena que llega hasta delante del ojo; segmentación antenal y del mazo variable; espinas propodeales variables. 26

26. Dorso mesosomal aplanado o convexo y sin suturas impresas. 27

Dorso mesosomal variable pero con suturas transversales. 32

27. Nódulo peciolar alargado y semicilíndrico; espolones de la mesotibia y metatibias ligeramente pectinadas; mandíbulas esbeltas y con el borde masticador oblicuo. Hylomyrma (Fig. 68)

Nódulo peciolar bien definido, de lo contrario entonces presenta espinas propodeales; espolón metatibial simple y en caso contrario la mandíbula es más o menos triangular y su borde masticador es transversal. 28

28. Surcos antenales presentes; carenas frontales se extienden hasta el borde occipital; espolón presente al final de la metatibia; mandíbulas con más de seis dientes. Tetramorium (Fig. 69)

Surcos antenales ausentes; carenas frontales no llegan más allá de los ojos; metatibias sin espolón apical; mandíbula con numero de dientes variables. 29

29. Pronoto anterolateralmente anguloso; área anterocentral del clípeo con un par de carenas longitudinales distalmente divergentes. Rogeria (Fig. 70)

Pronoto redondeado; área anterocentral del clípeo sin un par de carenas longitudinales distalmente divergentes. 30

30. Lóbulo mediano del clípeo es bastante elevado, formando una lámina delgada bidentada que se une con la carena frontal y termina en dos dientes romos en el borde anterior clípeal. Adelomyrmex (Fig. 71)

Sin esta combinación de caracteres. 31

31. Pedúnculo del peciolo más corto que el largo del nódulo peciolar, peciolo y pospeciolo con espinas y protuberancias; antena de once a doce segmentos; clípeo con un lóbulo anteromediano que sobrelapa las mandíbulas. Nesomyrmex (Fig. 72)

Pedúnculo del pecíolo más largo y delgado que el nódulo peciolar, peciolo y pospeciolo sin espinas o protuberancias; antena siempre con doce segmentos; clípeo sin un lóbulo que sobrelapa las mandíbulas. Temnothorax (Fig. 73)

32. Peciolo en vista lateral cilíndrico, sin nódulo; antena con diez segmentos; clípeo bicarinado. Xenomyrmex (Fig. 74)

Peciolo con nódulo bien desarrollado. 33

33. Antenas con doce segmentos, maza apical de tres segmentos. 34

Antena de nueva a once segmentos; maza apical variable. 37

34. Clípeo con dos carenas longitudinales; palpos maxilares de dos segmentos y palpos labiales de dos. Monomorium (Fig. 75)

Clípeo sin carenas longitudinales. 35

35. Ojos planos y más atrás de la mitad de la cabeza; propodeo sin espinas; nódulo pospeciolar tan largo como el nódulo del peciolo y muy convexo; cuerpo usualmente liso. Megalomyrmex (Fig. 76)

Ojos por lo menos algo convexos y a media distancia cefálica o más adelante; propodeo usualmente con espinas; cuerpo usualmente con esculturación. 36

36. Maza ausente o no diferenciable, engrosándose paulatinamente hacia su ápice; cabeza posteriormente se estrecha en un cuello; ojo grande, el diámetro máximo es más largo que la longitud del primer segmento del funículo de la antena. Aphaenogaster (Fig. 77)

Maza de cuatro segmentos; cabeza cuadrada y sin prolongaciones posteriores; ojo pequeño, el diámetro máximo es menor que la longitud del primer segmento del funículo de la antena. Stenamma (Fig. 78)

37. Antenas de nueve segmentos; palpos maxilares de dos segmentos; propodeo sin espinas; seta anterocentral del clípeo ausente. Carebara (Fig. 79)

Antenas de nueve a once segmentos; palpos maxilares de uno a seis segmentos; si las antenas son de nueve segmentos, entonces el propodeo tiene dos espinas; seta mediana del clípeo variable. 38

38. Antena de diez segmentos; área central del clípeo elevada abruptamente y bordeada por carenas paralelas que forman la parte posterior de la elevación central. Carebarella (Fig. 80) 

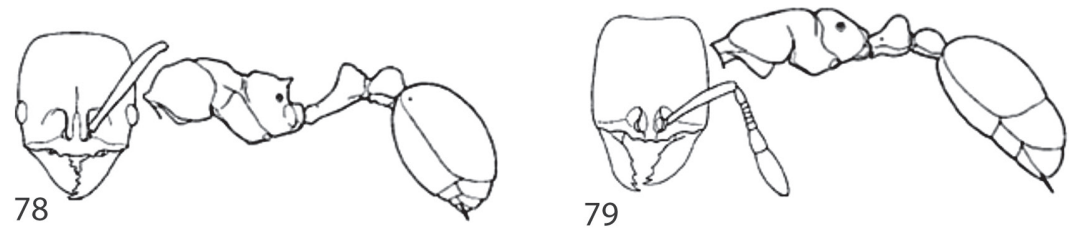

79
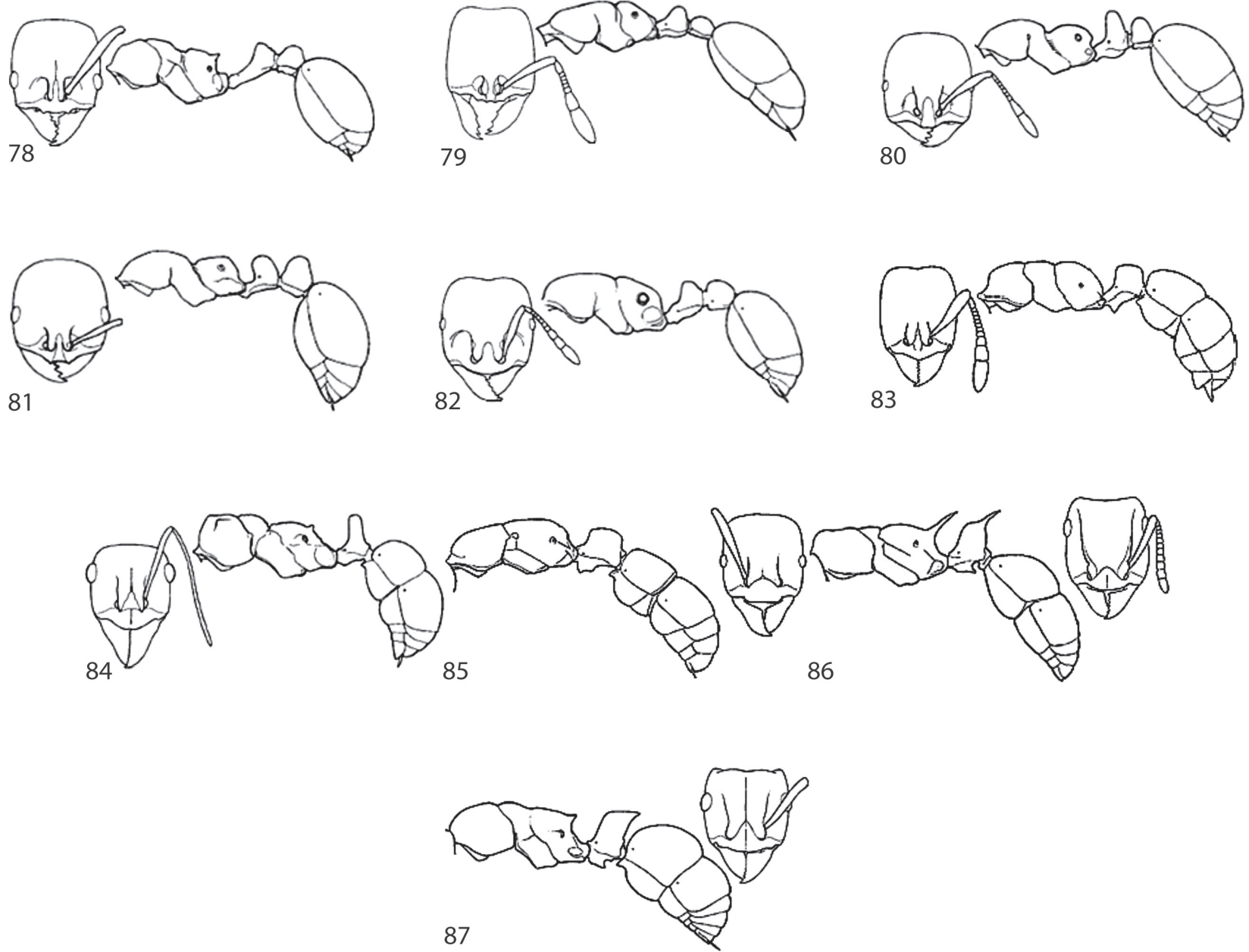

Fig. 78. Stenamma. Fig. 79. Carebara. Fig. 80. Carebarella. Fig. 81. Solenopsis. Fig. 82. Tranopelta. Fig. 83. Typhlomyrmex. Fig. 84. Ectatomma. Fig. 85. Gnamptogenys. Fig. 86. Acanthoponera. Fig. 87. Heteroponera. Figuras 78, 79, 80,81 y 82 modificadas de Fernández (2003b). Figuras 83, 84, 85, 86 y 87 modificadas de Lattke (2003).

Antena de diez a once segmentos, área central del clípeo no elevada y bordeada por carenas. 39

39. Antenas con diez segmentos, maza antenal de dos segmentos. Solenopsis (Fig. 81)

Antenas con once segmentos, maza antenal de tres segmentos. Tranopelta (Fig. 82)

\section{Ectatomminae}

1. Enculturación del cuerpo débil; antenas con maza apical de tres o cuatro segmentos. Typhlomyrmex (Fig. 83)

Enculturación del cuerpo fuerte: líneas, arrugas, costillajes, estrías o gránulos; antenas sin maza apical. 2
2. Mesonoto prominente en perfil, diferenciado del propodeo por una fisura transversa; pronoto usualmente con dos o tres tubérculos; ápice de la prototibia en vista lateral externa con una seta cerca de la base del espolón. Ectatomma (Fig. 84)

Mesonoto no prominente en perfil; propodeo y mesonoto formando una superficie continua o casi continua en perfil; pronoto sin tubérculos; ápice de la prototibia sin una seta cerca de la base del espolón. Gnamptogenys (Fig. 85)

\section{Heteroponerinae}

1. Garras tarsales presentan un lóbulo basal prominente; ápice del peciolo prolongado posteriormente en 
un diente agudo; propodeo con espinas prominentes. Acanthoponera (Fig. 86)

Garras tarsales sin un lóbulo basal prominente; el peciolo sin diente apical o con un diente pequeño; propodeo angulado o con dientes cortos. Heteroponera (Fig. 87)

\section{DISCUSIÓN}

Estudios anteriores dividen a Paratrechina en seis géneros, entre ellos Nylanderia, dejando las especies de Paratrechina con una sola especie en Costa Rica, las otras especies ahora como Nylanderia (La Polla et al., 2010), en la presente clave se incluye ambos géneros. Por otro lado el género Amblyopone se separó recientemente en tres géneros (Yoshimura \& Fisher, 2012), cambiando las especies que viven en Costa Rica al género Stigmatomma. Además la clave no incluye Bariamyrma, según Longino (2013) de este género se cuenta con unas cuantas reinas colectadas, solo hay descripción del holotipo (Lattke, 1990).

Las subfamilias de hormigas cazadoras Heteroponerinae y Ectatomminae, anteriormente del clado poneroide, se ubican en la presente clave dentro del clado formicoide (Cuadro 1), con una mayor cercanía a Myrmicinae y Formicinae, considerando poneroide un clado monofiletico (Fernández \& Arias-Penna, 2008). Publicaciones como The Ants de Hölldobler y Wilson (1990) y la clave para hormigas neotropicales de Palacio y Fernández (2003) es de la poca literatura que ofrece una descripción para el género Bothriomyrmex. En los últimos años se han realizado cambios en la taxonomía actual por lo que el uso de claves anteriores como la de Bolton (1994), a pesar de ser una gran herramienta para identificar hormigas del mundo puede estar sujeta a limitantes debido a dichos cambios (La Polla et al., 2010; Ward, 2010; Yoshimura \& Fisher, 2012).

Se considera de importancia para el estudio de las hormigas la guía de identificación de hormigas del mundo de Bolton (1994), además Bolton (2003) en el que se presenta una lista de revisiones a nivel de especies para cada género, también las claves en Palacio y Fernández (2003) para subfamilias y géneros de la región Neotropical. Además Ward (2010) presenta un cuadro actualizado de las publicaciones más recientes, organizado por género de hormigas y región geográfica. Por otro lado el sitio http://www.antweb.org/ mantenida por la Academia de Ciencias de California, ha documentado, a través de imágenes de alta calidad, la diversidad de hormigas de todo el planeta (Hubert, Fernández \& Majer, 2012). En http://www.hindawi.com/journals/psyche/ ants.parasites/ se pueden encontrar un gran número de artículos de taxonomía de hormigas de la revista Psyche (Agosti \& Johnson, 2003). Por su parte Longino (2013) en su página de hormigas de Costa Rica presenta información de distribución, historia natural, bibliografía y fotografías para especies, este puede ser uno de los recursos de mayor utilidad para identificar los géneros y especies de hormigas de Costa Rica (Branstetter \& Sáenz, 2012).

Se concluye que la presente clave puede ser una herramienta útil para futuros estudios relacionados con la biología y la diversidad de hormigas en Costa Rica.

\section{AGRADECIMIENTOS}

Agradezco a mi padre Marvin Gutiérrez Mejías y a mi madre Elizabeth Martínez Navarro por todo su esfuerzo para con migo. Además a Paul E. Hanson Snortum por su apoyo durante la realización de este trabajo.

\section{REFERENCIAS}

Agosti, D., \& Johnson, N. F. (2003). La nueva taxonomía de hormigas. Capitulo 2. (pp. 45-48) En Fernández, F. (2003). Introducción a las hormigas de la región neotropical. Colombia: Instituto de Investigación de Recursos Biológicos Alexander von Humboldt.

Arcila, A. M., \& Lozano-Zambrano, F. H. (2003). Hormigas como herramientas para la bioindicación y el monitoreo. Capítulo 9. (pp. 159-166) En Fernández, F. (2003). Introducción a las hormigas de la región Neotropical. Colombia: Instituto de Investigación de Recursos Biológicos Alexander von Humboldt.

Bolton, B. (1994). Identification guide to the ants of the world. Cambridge: Harvard University Press.

Bolton, B. (2003). Synopsis and Classification of Formicidae. Memoirs of American Entomological Institute, 71, 1-370.

Bolton, B. (2007). Taxonomy of the dolichoderine ant genus Technomyrmex Mayr (Hymenoptera: Formicidae) based on the worker caste. Contributions of the American Entomological Institute, 35(1), 1-150.

Brady, S., Schultz, T., Fisher, B., \& Ward, P. (2006). Evaluating alternative hypotheses for the early evolution and diversification of ants. Proceedings of the National Academy of Sciences of the United States of America, 103(48), 18172-18177.

Brandão, C. R. F. (2003). Subfamilia Leptanilloidinae. Capítulo 19. (pp. 287-290) En Fernández, F. (2003). Introducción a las hormigas de la región Neotropical. Colombia: Instituto de Investigación de Recursos Biológicos Alexander von Humboldt. 
Branstetter, M.G., \&Sáenz, L. (2012). Las hormigas (Hymenoptera: Formicidae) de Guatemala. (pp. 221-268) En Cano, E. B., \& Schuster, C. (Eds.). Biodiversidad de Guatemala. Guatemala: Universidad del Valle de Guatemala.

Brown, W. L; Jr., \& Kempf, W. W. (1960). A world revision of the ant tribe Basicerotini. Studia Entomológica, 3, 161-250.

Cuezzo, F. (2003). Subfamilia Dolichoderinae. Capítulo 20. (pp. 291-298) En Fernández, F. (2003). Introducción a las hormigas de la región Neotropical. Colombia: Instituto de Investigación de Recursos Biológicos Alexander von Humboldt.

Della, T. M. C. (2003). Hormigas de importancia económica en la región neotropical. Capítulo 24. (pp. 337-349) En Fernández, F. (2003). Introducción a las hormigas de la región Neotropical. Colombia: Instituto de Investigación de Recursos Biológicos Alexander von Humboldt.

Estrada, C., \& Fernández, C. (1999). Diversidad de hormigas (Hymenoptera: Formicidae) en un gradiente sucesional del bosque nublado (Nariño, Colombia). Revista de Biología Tropical, 47(1-2), 189-201.

Escalante, A., Ponce, J., \&Vásquez, M.(2006). Géneros de hormigas (Hymenoptera: Formicidae) del Estado de Michoacán. Biológicas, 8, 80-101.

Fernández, F. (2003a). Subfamilia Formicinae. Capítulo 21. (pp. 299-306) En Fernández, F. (2003). Introducción a las hormigas de la región Neotropical. Colombia: Instituto de Investigación de Recursos Biológicos Alexander von Humboldt.

Fernández, F. (2003b). Subfamilia Myrmicinae. Capítulo 22. (pp. 307-330) En Fernández, F. (2003). Introducción a las hormigas de la región Neotropical. Colombia: Instituto de Investigación de Recursos Biológicos Alexander von Humboldt.

Fernández, F., \& Sendoya, S. (2004). Synonymic list of Neotropical ants (Hymenoptera: Formicidae). Biota Colombiana, 5(1), 3-105.

Fernández, F., \& Arias-Penna, T. M. (2008). Las hormigas cazadoras en la región Neotropical. Capítulo 1. (pp.3-40) En Jiménez, E., Fernández, F., \& Arias-Penna, T. M. (2006). Sistemática, biogeografía y conservación de las hormigas cazadoras de Colombia. Colombia: Instituto de Investigación de Recursos Biológicos Alexander von Humboldt.

Folgrarait, P. J. (1998). Ant Biodiversity and its relationship to ecosystem functioning: a review. Biodiversity and Conservation, 7(9), 1221-1244

Hanson, P. E., \& Longino, J. T. (2006). Hormigas (Formicidae). Capítulo 16. (pp.644-694) En Hanson, P.E., \& Gauld, I.D. (2006). Hymenoptera de la Región Neotropical. Florida, EEUU: Memoirs of American Entomological Institute.

Hölldobler, B., \& Wilson, E.O. (1990). The Ants. Cambridge, EEUU: Harvard University Press.
Hubert, J. C., Fernández, F., \& Majer, J. (2012). Advances in Neotropical Myrmecology. Psyche, 2012, 1-3. doi:10.1155/2012/286273

Jaffé, K. (2004). El mundo de las hormigas. Venezuela: Ediciones de la Universidad Simón Bolívar.

La Polla, J., Brady S., \& Shattuck S. (2010). Phylogeny and taxonomy of Prenolepisgenus-group of ants (Hymenoptera: Formicidae). Systematic Entomology, 35, 118-131.

Lattke, J. (1990). A new genus of myrmicine ants (Hymenoptera: Formicidae) from Venezuela. Insect Systematics \& Evolution, 21(2), 173-178.

Lattke, J. E. (2003). Subfamilia Ponerinae. Capítulo 16. (pp. 261-276) En Fernández, F. (2003). Introducción a las hormigas de la región Neotropical. Colombia: Instituto de Investigación de Recursos Biológicos Alexander von Humboldt.

Longino, J. T. (2013). Ants of Costa Rica. Recuperado de http:// academic.evergreen.edu/projects/ants/

Mackay, W. P., \& Mackay, E. (1989). Clave de los géneros de hormigas en México (Hymenoptera: Formicidae). (pp. 1-82) En Quiroz, L. N., \& Garduño, M. P. (Eds.). (1989). Segundo Simposio Nacional de Insectos Sociales. México: Sociedad Mexicana de Entomología.

Mackay, W. P. (2003). Subfamilia Cerapachyinae. Capítulo 17. (pp. 277-280) En Fernández, F. (2003). Introducción a las hormigas de la región Neotropical. Colombia: Instituto de Investigación de Recursos Biológicos Alexander von Humboldt.

Martínez, M. D., \& Martínez, L. (2011). Cita nueva de la hormiga exótica Hypoponera punctatissima (Roger, 1859) (Hymenoptera: Formicidae: Ponerinae) en la Península Iberica y su importancia médica. Heteropterus Revista de Entomología, 11(1), 157-160.

Nicholls, C. (2008). Control biológico de insectos: un enfoque agroecológico. Colombia: Editorial Universidad de Antioquia.

Olivero, D., Guerrero, R., \& Escárraga M. (2009). Claves taxonómicas para las hormigas cazadoras (Hymenoptera: Formicidae: Ponerinae S.STR., Ectatomminae, Heteroponerinae) de la Sierra Nevada de Santa Marta, Colombia. Revista Intropica, 4, 17-28.

Palacio, E. E. (2003). Subfamilia Ecitoninae. Capítulo 18. (pp. 281-286) En Fernández, F. (2003). Introducción a las hormigas de la región Neotropical. Colombia: Instituto de Investigación de Recursos Biológicos Alexander von Humboldt.

Palacio, E. E., \& Fernández, F. (2003). Claves para las subfamilias y géneros. Capitulo 15. (pp. 230-260) En Fernández, F. (2003). Introducción a las hormigas de la región Neotropical. Colombia: Instituto de Investigación de Recursos Biológicos Alexander von Humboldt. 
Smith, M. R. (1939). Ants of the genus Macromischa Roger in the United States (Hymenoptera: Formicidae). Annals of Entomological Society of America, 32(3), 502-509.

Trager, J. C. (1984). A revision of the genus Paratrechina (Hymenoptera: Formicidae) of the continental United States. Sociobiology, 9(2), 51-162.

Ward. P. S. (2003). Subfamilia Pseudomyrmecinae. Capítulo 23. (pp. 331-333) En Fernández, F. (2003). Introducción a las hormigas de la región Neotropical. Colombia: Instituto de Investigación de Recursos Biológicos Alexander von Humboldt.
Ward, P. S. (2010). Taxonomy, phylogenetics and evolution. Chapter 1. (pp. 3-17) En Lach, L., Parr, C. L., \& Abbott, K. (Eds). (2010). Ant ecology. Oxford: OxfordUniversityPress.

Weber, N. A. (1934). Notes on neotropical ants, including the descriptions of new forms. Revista de Entomología (Rio de Janeiro), 4, 22-59.

Yoshimura, M., \&Fisher, B.L. (2012). A Revision of Male Ants of the Malagasy Amblyoponinae (Hymenoptera: Formicidae) with Resurrections of the Genera Stigmatomma and Xymmer. PLOS ONE, 7(3), e33325. doi:10.1371/journal. pone.0033325. 
